\title{
Climate change \& global warming, major challenges threatening the future food security for human beings and all other living organisms
}

\section{Editorial}

Today, more than ever, climatic change and global warming due to improper use of plants, deforestation, overgrazing in rangelands, industrialization, greenhouse effects, and excess of carbon dioxide $\left(\mathrm{CO}_{2}\right)$ emission to the atmosphere, coupled with increased evapotranspiration due to raising in temperature, reduced precipitation, and increased aridity and desertification threaten human beings as well as animals and all other living organisms universally. Climate change and global warming in addition to their adverse effects on food security due to reduction in crop production and yield have major health hazards on all life on the earth. It has been predicted that these problems will be more sever in the future with no relief throughout the world, particularly in the arid and semi-arid regions. These regions that are already under tremendous environmental (salinity, drought, heat) stresses, will be more affected and particularly will encounter more drought stress and water shortage as a result in reduced plants productivity and crop yields. It is widely believed among the scientists that the water shortage and limited water resources will be the most challenging to human beings in the future and may result in World War III. Considering the above challenges, a reduction in water usage by preventing any water wasted by runoff as well as using plants with lower water requirements and more tolerant to the environmental stresses (particularly, drought), afforestation, proper land management (especially, rangelands), saline agriculture, reclamation of salt-affected soils, erosion control (especially, biological control) are among the major initiatives and strategies to combat the inevitable severity of the future climate change and global warming. Otherwise, it may be impossible to provide sufficient food to feed the future world population, and consequently
Volume 7 Issue 2 - 2017

Mohammad Pessarakli

Department of Plant Sciences, the University of Arizona, Tucso, USA

Correspondence: Mohammad Pessarakli, Editor-in-Chief, Advances in Plants \& Agriculture Research, Professor, School of Plant Sciences, College of Agriculture and Life Sciences, The University of Arizona, Tucson, AZ 85721, USA, Email pessarak@email.arizona.edu

Received: June II, 2017 | Published: June 13,2017

global hunger will certainly result in war and destruction. Thus, there is an urgent need for implementing the above mentioned strategies to combat climate change and global warming. In addition, warning and educating the leaders of the countries from the consequences of this tragedy is extremely important and must be seriously taken into consideration. Ignoring this major problem will have catastrophic irreversible consequences to all life on the earth.

\section{Acknowledgements}

None.

\section{Conflict of interest}

The author declares no conflict of interest. 